\title{
Sustainable and Clean Utilization of Coal Gangue: Activation and Preparation of Citrate-Soluble Silicon Fertilizer
}

\section{Bo Lv ( $\sim$ Ivbo2158@126.com )}

Henan Polytechnic University https://orcid.org/0000-0002-9356-4862

\section{Zeya Zhao}

Henan Polytechnic University

\section{Xiaowei Deng}

Henan Polytechnic University

\section{Chaojun Fang}

Henan Polytechnic University

\section{Bobing Dong}

Henan Polytechnic University

\section{Research Article}

Keywords: coal gangue, available-silicon, diffraction peak, calcination, silicon fertilizer, high-temperature activation

Posted Date: November 10th, 2021

DOI: https://doi.org/10.21203/rs.3.rs-922926/v1

License: (c) (i) This work is licensed under a Creative Commons Attribution 4.0 International License. Read Full License

Version of Record: A version of this preprint was published at Journal of Material Cycles and Waste Management on May 12th, 2022. See the published version at https://doi.org/10.1007/s10163-022-01426-5. 


\section{Abstract}

Silicon ( $\mathrm{Si}$ ) fertilizer is of great significance to modern agricultural production; the citrate-soluble silicon fertilizer based on coal gangue is one way to protect the environment and meet the agricultural needs of China. In this study, we produced high-efficiency coal-gangue based silicon fertilizer by calcining a mixture of coal gangue, calcium carbonate $\left(\mathrm{CaCO}_{3}\right)$ and corn stalk powder at high-temperature (i.e., high-temperature activation technology); the effect of temperature and mixing ratio on the available-Si content of activated coal gangue was studied, followed by an analysis of the mechanism of available-Si formation. The results showed that the layered structure of coal gangue was severely damaged above 600 ${ }^{\circ} \mathrm{C}$, and the kaolin began to transform into metakaolin and other substances, where the available-Si content was not high (less than $10 \%$ ). When $\mathrm{CaCO}_{3}$ alone was added, the peak intensity of quartz and muscovite in coal gangue decreased significantly with the increase of $\mathrm{CaCO}_{3}$. However, $\mathrm{CaCO}_{3}$ mainly played a catalytic role in the entire calcination and activation process, forming only a small amount of calcium silicate on the contact surface with coal gangue; however, the available-Si content was still below $12.60 \%$. When corn stalk powder alone was added, the oxides of the corn stalk ash participated in the chemical reaction involving coal gangue, forming nepheline $\left(\mathrm{K}(\mathrm{Na}, \mathrm{K})_{3} \mathrm{Al}_{4} \mathrm{Si}_{4} \mathrm{O}_{16}\right)$ and other silicates, and the available-Si content was significantly higher than that with $\mathrm{CaCO}_{3}$. When coal gangue, $\mathrm{CaCO}_{3}$, and corn stalk powder were mixed and calcined, the available-Si content was as high as $22.97 \%$ under the synergistic effect of $\mathrm{CaCO}_{3}$ and corn stalk powder; the concentration of harmful heavy metals was below $0.025 \mathrm{mg} / \mathrm{L}$. The above is in line with the requirements of silicon fertilizer for use in agriculture, thus confirming the preparation of coal gangue-based silicon fertilizer in an efficient manner.

\section{Introduction}

As the second most abundant element in the soil, silicon ( $\mathrm{Si}$ ) is ubiquitous in plants, and plays a vital role in the growth of crops. The Si available from the soil has a positive effect on plant growth, promoting photosynthesis, growth of symbiotic beneficial microorganisms, resistance to pests and diseases, capture of beneficial components such as $\mathrm{P}, \mathrm{Ca}, \mathrm{K}$, and $\mathrm{Mg}$, resistance to salt and water stress, and reduction of heavy metal toxicity (Xiao et al. 2016; Xiao et al. 2021; Yan et al. 2018). However, the $\mathrm{Si}$ in the soil is present mainly in the form of quartz and secondary clay minerals, which cannot be directly absorbed by plants. Only monosilicic acid below $1 \%$ can be absorbed and utilized by plants, and is called available-Si. Moreover, with the continuous promotion of the large-scale agricultural model in China, the available-Si in the soil gradually decreases, which may have a potential negative impact on plant growth (Song et al. 2014; Samaddar et al. 2019). Therefore, scientific and reasonable application of silicon fertilizer for the timely supplementation of the available$\mathrm{Si}$ in the soil has become a focus of modern agricultural production.

Currently, silicon fertilizer is being used in the cultivation of rice, soybean, melon, lettuce, pomegranate and sugarcane, and has achieved good results (Mandlik et al. 2020; Zhu et al. 2019). Silicon fertilizer comes mainly from two sources. The first source is a mixture of silicate and metasilicate formed through the artificial combination of water glass (or quartz sand) and carbonates, i.e., water-soluble silicon fertilizer which mainly includes salicylic acid, and silicates of calcium, sodium, potassium, and magnesium. The fertilizer has available-Si above $60 \%$, with the characteristics of quick action and easy direct absorption. However, the production cost of water-soluble silicon fertilizer is relatively high with lower yield, making it difficult to meet the large demand for silicon fertilizer in modern agriculture from this source (Chen and Committee 2018; Pati et al. 2016). On the other hand, steel slag from industrial solid waste, slag, fly ash and black liquor from the paper industry can be activated to form the citrate-soluble silicon fertilizer, which has a low effective silicon content, mostly less than $35 \%$. The silicon fertilizer so produced has a delayed effect but exhibits high performance, and is effective over a long period; it also realizes the secondary resource utilization of solid waste while mitigating environmental pollution, which has high developmental and application prospects (Ning et al. 2016). 
Coal gangue, which is the main source of citrate-soluble silicon fertilizer, is a solid waste produced in the process of coal processing and utilization. It is a type of low-carbon, hard black rock with $\mathrm{SiO}_{2}$ as its main component, accompanied by abundant trace elements such as B, Cu, Co, Zn, and Mn (Wang and Wang 2018). The Si component of coal gangue is suitable for producing silicon fertilizer, while the presence of trace elements can promote crop growth and development (Wang et al. 2020). However, since the silicon in coal gangue cannot be directly absorbed and utilized by plants, it is necessary to convert crystalline silicon dioxide into available-Si that can be absorbed and utilized by plants, so as to realize its use in agriculture. The activation processes commonly used at present to achieve this end are mainly divided into four types, namely mechanical activation, microbial activation, chemical activation and high-temperature activation.

In the mechanical activation process, mechanical energy is mainly used to cause physical and chemical changes in the target mineral, which promotes imperfections or displacements in the crystal lattice and even the amorphous state, thereby improving the dissolution behavior of useful chemical components (Said et al. 2020). Liu et al. (2020) used mechanical grinding to activate potassium-containing silicate minerals, thereby increasing the release of silicon and potassium, to prepare silicon-potassium fertilizers. Countries like Japan and North Korea often adopt this activation method for the preparation of silicon fertilizer, achieving good economic benefits in rice cultivation (Cai 2017; Lee and Kim 2006; Makabe-Sasaki et al. 2014). However, the available-Si content of the silicon fertilizer produced by mechanical activation is generally low, which is insufficient to meet the needs of large-scale agricultural production. The aim of the microbial activation process is mainly to degrade the target minerals using the metabolic process of the microorganisms themselves (i.e., use of silicate bacteria and bacillus megaterium) to achieve the dissolution of P, K and Si, thereby producing microbial fertilizers (Wang et al. 2010). The microbial activation process exhibits high efficiency in dissolving $P$ and $\mathrm{K}$ from coal gangue, but its efficiency in dissolving Si is relatively low (Bi et al. 2019; Dopson et al. 2006; Li et al. 2014). The chemical activation process mainly uses acid, alkali, and salt solutions to destroy the chemical bonds in the target minerals, thereby increasing the available-Si (Gao et al. 2015). However, this process is currently in the laboratory stage of development. Sun Hongbin (2008) activated a mixture of coal gangue and straw in $\mathrm{KOH}$ and $\mathrm{H}_{2} \mathrm{O}_{2}$ solutions to prepare silicon fertilizer, but the Si that was finally available in the activated coal gangue was only approximately $1.0-$ $3.5 \%$; it is thus difficult to prepare high-efficiency silicon fertilizer using chemical activation.

The high-temperature activation process mainly utilizes a high-temperature environment to promote the reaction of target minerals with other reagents, so as to transform their stable structure into a morphological structure with multiple micropores, multiple broken bonds, increased solubility, and higher internal energy. Finally, the Si in the target mineral is activated into available-Si (Li et al. 2013; Li et al. 2016). In order to improve the rate of extraction of available-Si from the target mineral at high temperature, activators such as calcium carbonate, potassium carbonate, sodium carbonate, diethanolamine and alkali metal salts are necessary, the reactions resulting in citrate-soluble silicon fertilizers such as silicon potassium fertilizer, silicon calcium fertilizer and silicate micro-fertilizer. Yao et al. (2014) used steel slag as a raw material and prepared a fused potassium silicate fertilizer at high temperature by adding potassium carbonate. It has been reported that the preparation of silicon fertilizer by high-temperature activation is a very viable and relatively simple process which is particularly suitable for industrial applications. However, few studies have been carried out on the preparation of coal-gangue based silicon fertilizer using high-temperature activation technology.

In this study, coal gangue mixed with calcium carbonate and corn stalk powder is used as a raw material to produce gangue-based silicon fertilizer through high-temperature activation. Combining X-ray diffraction (XRD) and Fourier transformed infrared (FT-IR) measurement with silicomolybdenum blue spectrophotometry, the influence of calcination temperature and mixing ratio on the available-Si in activated coal gangue was initially explored; the optimal preparation procedure was then investigated. Finally, the leaching test was used to study the release characteristics of coal-gangue based silicon fertilizer, and its reliability verified, thereby providing a theoretical basis for use of coal-gangue based silicon fertilizer in agriculture. 


\section{Methods And Materials \\ 2.1 Methods}

In this study, coal gangue (10 g sample for each experiment) mixed with $\mathrm{CaCO}_{3}$ and corn stalk powder was used to prepare coal gangue-based silicon fertilizer using a high- temperature activation furnace (DC-B-2, Beijing Original Technology Co., Ltd., China). In order for the high-temperature calcination process to be completed, the calcination time was set to 120 s. Moreover, using XRD (D8 Advance, Bruker Axs GmbH, German) and FT-IR (Vertex 80v, Bruker Axs GmbH, German) measurement technologies, the changes in the composition and functional groups of the samples were obtained to analyze the mechanism of formation of silicon fertilizer from coal gangue. Herein, the X-ray generator was equipped with a copper target $\mathrm{x}$-ray tube operating at $40 \mathrm{kV}$ and $26 \mathrm{~mA}$ (radiation wavelength $\lambda=0.154 \mathrm{~nm}$ ). In the measurement process, XRD spectra were acquired at room temperature over the $2 \theta$ range of $5^{\circ}-35^{\circ}$ at $0.05^{\circ}$ intervals with a measurement time of 1 second per $2 \theta$ intervals. Moreover, FT-IR spectra were obtained on $\mathrm{KBr}$ pellets ( $1 \mathrm{mg}$ of samples powder and $200 \mathrm{mg}$ of $\mathrm{KBr}$, pressed into $13 \mathrm{~mm}$ diameter discs at a pressure of $10 \mathrm{Ton})$. FT-IR spectra were recorded on a Bruker Vertex 80v Fourier Transform Infrared Spectrometer with a resolution of $4 \mathrm{~cm}^{-1}$, by 64 scans in the region between 4000 and $450 \mathrm{~cm}^{-1}$. In addition, silicon molybdenum blue spectrophotometry was used to determine the available-Si content of the sample, to analyze the influence of various factors on the activation process.

\subsubsection{Single factor exploration}

In order to analyze the influence of the calcination temperature, the mixing ratio of $\mathrm{CaCO}_{3}$ (or corn stalk powder) to coal gangue, and the available-Si content in the activated coal gangue produced-corresponding to five levels for each factor to be studied-were determined, and are shown in Table 1.

Table 1

The levels of each factor

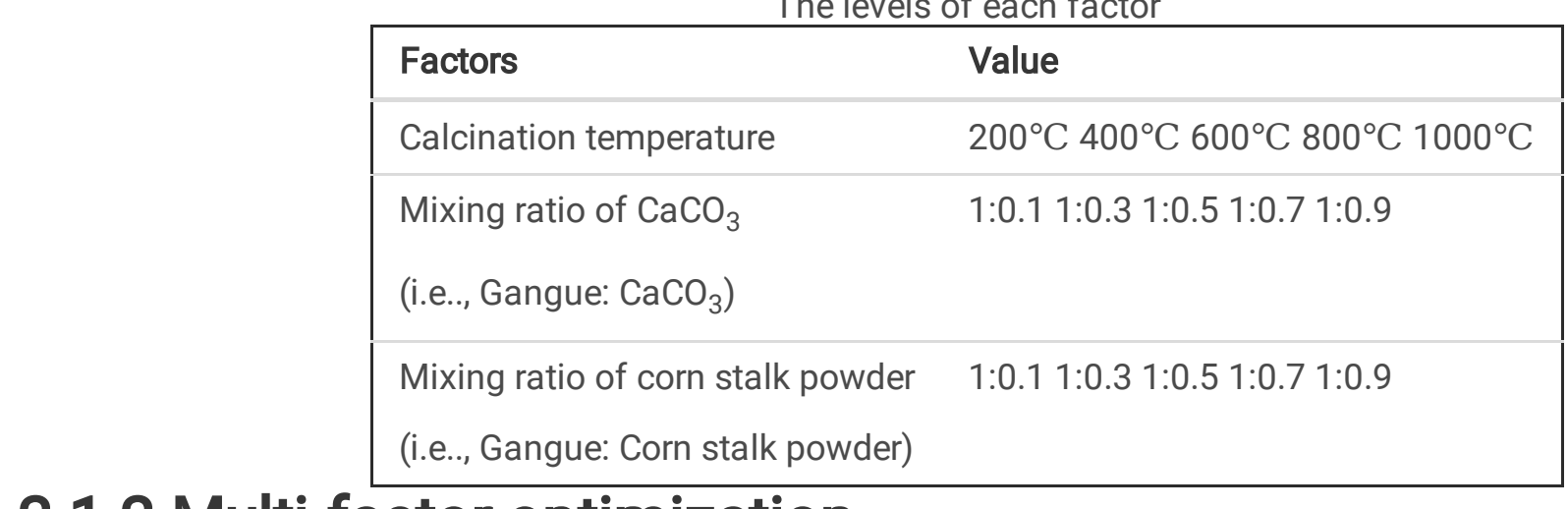

\subsubsection{Multi-factor optimization}

In order to obtain the optimal mixing ratio of coal gangue, $\mathrm{CaCO}_{3}$ and corn stalk powder for the efficient preparation of coal-gangue based silicon fertilizer, 25 sets of mixed calcination experiments were performed, the results of which are shown in Table 2. 
Table 2

Mixing ratio configuration of the three substances

\begin{tabular}{|llll|}
\hline No. & Gangue: $\mathrm{CaCO}_{3}$ :Corn stalk powder & No. & Gangue: $\mathrm{CaCO}_{3}$ : Corn stalk powder \\
\hline 1 & $1: 0.1: 0.1$ & 14 & $1: 0.5: 0.7$ \\
\hline 2 & $1: 0.1: 0.3$ & 15 & $1: 0.5: 0.9$ \\
\hline 3 & $1: 0.1: 0.5$ & 16 & $1: 0.7: 0.1$ \\
\hline 4 & $1: 0.1: 0.7$ & 17 & $1: 0.7: 0.3$ \\
\hline 5 & $1: 0.1: 0.9$ & 18 & $1: 0.7: 0.5$ \\
\hline 6 & $1: 0.3: 0.1$ & 19 & $1: 0.7: 0.7$ \\
\hline 7 & $1: 0.3: 0.3$ & 20 & $1: 0.7: 0.9$ \\
\hline 8 & $1: 0.3: 0.5$ & 21 & $1: 0.9: 0.1$ \\
\hline 9 & $1: 0.3: 0.7$ & 22 & $1: 0.9: 0.3$ \\
\hline 10 & $1: 0.3: 0.9$ & 23 & $1: 0.9: 0.5$ \\
\hline 11 & $1: 0.5: 0.1$ & 24 & $1: 0.9: 0.7$ \\
\hline 12 & $1: 0.5: 0.3$ & 25 & $1: 0.9: 0.9$ \\
\hline 13 & $1: 0.5: 0.5$ & & \\
\hline
\end{tabular}

\subsubsection{Leaching experiment}

The leaching experiment on coal-gangue based silicon fertilizer is shown in Fig. 1; the release characteristics of heavy metal ions were studied to verify the safety and applicability of the coal-gangue based silicon fertilizer. The equipment used in the leaching experiment includes a plastic basin with holes at the bottom, and a filter tray for filtering the leachate. The plastic basin contained three layers of material, the upper and bottom layers consisting of sand while the sample constituted the middle layer (i.e., the sand as the control group, and the silicon fertilizer as the experimental group). The water used in the leaching experiment was deionized water; the material in the basin was subjected to leaching every five days, and the heavy metal ion content in the filtered water was measured using the inductive coupled plasma emission spectrometer (ICP).

\subsection{Materials}

\subsubsection{Coal gangue}

The coal gangue used in the experiment comes from the Shendong mining area in Inner Mongolia, China. Figure 2(a) is the FT-IR spectrum of coal gangue, with its characteristic absorption curve. Here, $3697 \mathrm{~cm}^{-1}$ and $3620 \mathrm{~cm}^{-1}$ are the vibrations in the outer hydroxyl group (i.e., structural water) and inner hydroxyl group (i.e., interlayer water), respectively, of kaolin in coal gangue (Yan 2018); the absorption peak at $1430 \mathrm{~cm}^{-1}$ is mainly formed by hydroxyl bending vibration. The adsorption peaks at $942 \mathrm{~cm}^{-1}$ (back peak) and $912 \mathrm{~cm}^{-1}$ correspond to the bending vibrations of the inner surface hydroxyl group and inner hydroxyl group, respectively (Castellano et al. 2010; Makó et al. 2006), and the absorption peaks at 1100,695 and $473 \mathrm{~cm}^{-1}$ are attributed to the stretching vibration, flexural vibration and rocking vibration of the TOT bond where $\mathrm{T}$ is Al and Si (Markovic et al. 2003). Moreover, the absorption peaks at 539 and $431 \mathrm{~cm}^{-1}$ may be attributed to $\mathrm{Si}-\mathrm{O}-\mathrm{Ai}^{\mathrm{VI}}$, which overlaps with the absorption vibration of the Si-O-Si bond (Guo et al. 2016). From the XRD spectrum in Fig. 2(b), the coal gangue is seen to be mainly composed of quartz, kaolinite and muscovite. Si in coal gangue exists 
mainly in the form of $\mathrm{SiO}_{2}$ and silicate, which have relatively stable phase structures, requiring activation treatment in order to produce effective silicon fertilizer.

\subsubsection{Corn stalk powder}

The corn stalk powder comes from farmland near the Shendong mining area in Inner Mongolia, China. For better mixing of the sample, the corn stalk powder was ground to - 200 mesh size. The metal oxide content of corn stalk ash at different calcination temperatures is shown in Table 3 below.

Table 3 shows that the metal oxides and corn stalk ash contents are roughly the same at different calcination temperatures. The main oxides are $\mathrm{SiO}_{2}, \mathrm{~K}_{2} \mathrm{O}, \mathrm{CaO}$ and $\mathrm{MgO}$, which react with the silica-containing ore in coal gangue, thereby promoting the activation of $\mathrm{Si}$ in the coal gangue.

Table 3

Metal oxide content of corn stalk ash at different calcination temperatures

\begin{tabular}{|llllllllllll|}
\hline $\begin{array}{l}\text { Temperature/ } \\
{ }^{\circ} \mathrm{C}\end{array}$ & $\mathrm{SiO}_{2}$ & $\mathrm{Al}_{2} \mathrm{O}_{3}$ & $\mathrm{Fe}_{2} \mathrm{O}_{3}$ & $\mathrm{~K}_{2} \mathrm{O}$ & $\mathrm{CaO}$ & $\mathrm{MgO}$ & $\mathrm{SO}_{3}$ & $\mathrm{P}_{2} \mathrm{O}_{5}$ & $\mathrm{Na}_{2} \mathrm{O}$ & $\mathrm{MnO}$ & $\mathrm{Cl}$ \\
\hline 200 & 60.823 & 0.985 & 1.026 & 16.314 & 9.251 & 1.665 & 1.324 & 1.139 & 0.184 & 0.36 & 4.19 \\
\hline 400 & 61.358 & 1.038 & 1.257 & 15.098 & 10.067 & 1.709 & 1.45 & 1.682 & 0.106 & 0.201 & 3.011 \\
\hline 600 & 62.071 & 1.254 & 1.304 & 14.207 & 10.804 & 1.511 & 1.506 & 1.809 & 0.081 & 0.116 & 2.627 \\
\hline 800 & 66.752 & 1.308 & 1.352 & 11.024 & 11.038 & 1.305 & 1.527 & 1.934 & 0.032 & 0.109 & 1.024 \\
\hline 1000 & 67.25 & 1.485 & 1.407 & 11.069 & 11.051 & 1.017 & 1.71 & 2.011 & 0.010 & 0.021 & 0.92 \\
\hline
\end{tabular}

\subsection{Evaluation}

In order to study the activation efficiency for coal gangue under different conditions, the available Si content is used as an evaluation index, calculated by Eq. (1).

$$
\mathrm{k}=\frac{m}{m_{o}} \times 100
$$

1

where $k$ is the available Si content, as \%; $m$ is the mass of available Si in the activated sample in $g ; m_{O}$ is the mass of the activated sample in $\mathrm{g}$.

\section{Results And Discussion \\ 3.1 Results}

\subsubsection{Single factor exploration}

The coal gangue was subjected to calcination under various operating conditions, as shown in Fig. 3. The available-Si in coal gangue is different at different calcination temperatures, showing a gradually increasing trend with increase in temperature. When the calcination temperature reaches $600{ }^{\circ} \mathrm{C}$, the available-Si increases rapidly; while available-Si is $6.18 \%$ at $400{ }^{\circ} \mathrm{C}$, it is $8.19 \%$ at $600{ }^{\circ} \mathrm{C}$, the value then increasing slowly with temperature, indicating that the Si component of coal gangue is activated at $600{ }^{\circ} \mathrm{C}$. However, the overall percentage of available-Si is not high $(k<10 \%)$. 
In the subsequent experiments where calcination is carried out after mixing $\mathrm{CaCO}_{3}$ and then corn stalk powder, the calcination temperature is set to $600{ }^{\circ} \mathrm{C}$. In the calcination experiment involving coal gangue mixed with $\mathrm{CaCO}_{3}$, the available-Si content of the calcined coal gangue is significantly better than that of the calcined coal gangue obtained through the calcination of coal gangue alone. With the increase of the mixing ratio, the available-Si content of calcined coal gangue increases slightly. Especially, when the mixing ratio of coal gangue and $\mathrm{CaCO}_{3}$ increases to 1:0.9, the available-Si content can reach $12.60 \%$, indicating that $\mathrm{CaCO}_{3}$ can promote the activation process of coal gangue to a certain extent.

When coal gangue and corn stalk powder are mixed and calcined, available-Si increases with increase in mixing ratio. When the mixing ratio is $1: 0.9$, the available-Si content rises to $14.56 \%$, which is obviously better on the whole than that in activated coal gangue mixed with $\mathrm{CaCO}_{3}$; this may be due to the influence of oxides formed by the calcination of corn stalk powder.

\subsubsection{Multi-factor optimization}

In order to study the trends in available-Si during the calcination of coal gangue mixed with $\mathrm{CaCO}_{3}$ and corn stalk powder, a multi-factor experiment was used to obtain the best mixing ratio in each case, as shown in Fig. 4.

Overall, during the mixed calcination process, available-Si increases with the increase of $\mathrm{CaCO}_{3}$ (or corn stalk powder); there were two peaks, with available-Si of $22.97 \%$ and $22.55 \%$ at mixing ratios of 1:0.3:0.9 and 1:0.9:0.9, respectively. Moreover, the available-Si content of the activated samples basically meets the relevant regulations on silicon fertilizer (NY/T797-2004, China), i.e., $\mathrm{k}>10 \%$, which indicates that it is feasible to use a mix of coal gangue, $\mathrm{CaCO}_{3}$ and corn stalk powder to form a silicon fertilizer through calcination. From an economic point of view, in order to produce efficient coalgangue based silicon fertilizer, the optimal mixing ratio of coal gangue, $\mathrm{CaCO}_{3}$ and corn stalk powder should be 1:0.3:0.9. 
Table 4

Range analysis results

\begin{tabular}{|c|c|c|}
\hline Factor & $\mathrm{CaCO}_{3}$ & Corn stalk powder \\
\hline $\mathrm{K}_{0.1}$ & 64.763 & 46.200 \\
\hline $\mathrm{K}_{0.3}$ & 78.942 & 60.543 \\
\hline $\mathrm{K}_{0.5}$ & 66.923 & 76.480 \\
\hline $\mathrm{K}_{0.7}$ & 75.430 & 86.517 \\
\hline $\mathrm{K}_{0.9}$ & 82.439 & 98.759 \\
\hline$\square \mathrm{K}_{0.1}$ & 12.953 & 9.240 \\
\hline$\square \mathrm{K}_{0.3}$ & 15.788 & 12.109 \\
\hline$\square \mathrm{K}_{0.5}$ & 13.385 & 15.296 \\
\hline$\square \mathrm{K}_{0.7}$ & 15.086 & 17.303 \\
\hline$\square \mathrm{K}_{0.9}$ & 16.488 & 19.752 \\
\hline Range analysis & 3.535 & 10.512 \\
\hline Significance & \multicolumn{2}{|c|}{ Corn stalk powder $>\mathrm{CaCO}_{3}$} \\
\hline
\end{tabular}

Furthermore, the experimental results with extreme differences were analyzed to study the influence of $\mathrm{CaCO}_{3}$ and $\mathrm{corn}$ stalk powder on the available-Si content of calcined coal gangue, as shown in Table 4.

Table 4 shows that the effect of corn stalk powder on the available-Si content of calcined coal gangue is stronger than that of $\mathrm{CaCO}_{3}$, which is related to the different roles played by the above two additives in the Si activation of coal gangue.

\subsubsection{Leaching experiment}

Through the leaching experiment on coal gangue-based silicon fertilizer, the variations in the concentrations of harmful heavy metals in the filtrate were analyzed, as shown in Fig. 5. The main harmful heavy metals in coal-gangue based silicon fertilizer are $\mathrm{Cr}$ and $\mathrm{Ni}$, with the highest concentrations present being $0.025 \mathrm{mg} / \mathrm{L}$ and $0.01 \mathrm{mg} / \mathrm{L}$, respectively; the concentrations of these heavy metals decrease over time. The coal-gangue based silicon fertilizer also contains less harmful heavy metals, i.e., $\mathrm{Pb}$, As and $\mathrm{Cd}$, in concentrations less than $0.01 \mathrm{mg} / \mathrm{L}$. The concentrations of harmful heavy metal ions in coal-gangue based silicon fertilizer meet the safety requirements for agricultural applications according to the relevant standards for fertilizers (GB 8173 - 1987 and GBT 29163 - 2012).

\subsection{Discussion}

\subsubsection{Calcination temperature}

When the calcination temperature reaches $600^{\circ} \mathrm{C}$, the characteristic peaks of the hydroxyl groups are replaced by a series of new absorption bands, indicating that the layered structure of coal gangue has been completely damaged (Fig. 6). With the disappearance of the absorption peaks at 1100, 1033 and $1009 \mathrm{~cm}^{-1}$, a strong and broad absorption peak 
appeared at $1050 \mathrm{~cm}^{-1}$, which corresponds to the stretching vibration of the TOT bond in metakaolin, indicating the presence of metakaolinite in the calcined sample. The characteristic absorption bands of metakaolinite also contained the three newly formed bands corresponding to Si-O-Si bond vibration at $798 \mathrm{~cm}^{-1}$ and Si-O bending vibration at 694 and $486 \mathrm{~cm}^{-1}$ (Peng and Liu, 1982). Moreover, the original absorption peaks at 539 and $432 \mathrm{~cm}^{-1}$ disappeared, indicating the transition from $\mathrm{Si}-\mathrm{O}-\mathrm{Ai}^{\mathrm{VI}}$ to $\mathrm{Si}-\mathrm{O}-\mathrm{Ai}{ }^{\mathrm{IV}}$, which is also evidence of the formation of the amorphous metakaolinite phase. Therefore, calcination temperatures above $600{ }^{\circ} \mathrm{C}$ can promote the phase change of coal gangue, rapidly increasing its available-Si content.

The diffraction peaks in the XRD spectra of coal gangue samples are different at different temperatures shown in Fig. 7. When the temperatures are lower than $600{ }^{\circ} \mathrm{C}$, the diffraction peaks of coal gangue samples show little change, indicating that the composition and structure of coal gangue before and after heat treatment are similar, mainly composed of quartz, kaolinite and muscovite. The intensity of individual diffraction peaks corresponding to quartz increases with the increasing temperature, which may be caused by the burning of residual carbon in coal gangue, and the formation of amorphous $\mathrm{SiO}_{2}$ during the dehydroxylation of minerals such as kaolin and muscovite. As suggested by the disappearance of individual diffraction peaks of kaolinite and the formation of calcium silicate hydrate peaks, the hydroxyl group of kaolinite is being transformed into metakaolinite. When the calcination temperature exceeds $600{ }^{\circ} \mathrm{C}$, the diffraction peak corresponding to kaolinite gradually disappears, indicating that the kaolinite is being transformed into metakaolin at high temperature, thereby activating coal gangue. When the calcination temperature exceeds $800{ }^{\circ} \mathrm{C}$, the diffraction peak corresponding to muscovite gradually disappears, indicating that the muscovite in the coal gangue has undergone structural changes. However, due to the relatively low content of activated muscovite, the increase in available-Si in the coal gangue during this phase is not significant. Therefore, when the calcination temperature exceeds $600{ }^{\circ} \mathrm{C}$, although available-Si in calcined samples increases, the rate of increase is not significantly high.

\subsubsection{Calcination of coal gangue and $\mathrm{CaCO}_{3}$ mixture}

When coal gangue is calcined with $\mathrm{CaCO}_{3}$ at $600{ }^{\circ} \mathrm{C}$, the characteristic absorption curve changes significantly, as shown in Fig. 8. The absorption peaks at 2874, 2513, 1799, 1421, 875 and $712 \mathrm{~cm}^{-1}$ are characteristic peaks of carbonate, 3674 $\mathrm{cm}^{-1}$ corresponds to the stretching vibration of the free hydroxyl group, $1048 \mathrm{~cm}^{-1}$ indicates Si-O stretching vibration, and 562 and $484 \mathrm{~cm}^{-1}$ correspond to the bending vibration of Si-O. Here, 3674, 1048, 562 and $484 \mathrm{~cm}^{-1}$ constitute the characteristic peaks of hydroxy silicate (Li et al. 2021), indicating that a large amount of soluble silica minerals are formed by the calcination of coal gangue mixed with $\mathrm{CaCO}_{3}$. Moreover, increasing the mixing ratio of coal gangue to $\mathrm{CaCO}_{3}$ does not significantly change the solid phase structure formed, but only increases the intensity of the relevant characteristic peaks, indicating that the effective extraction rate of available-Si from coal gangue increases with increase in the mixing ratio.

From the XRD spectrum of coal gangue calcined with $\mathrm{CaCO}_{3}$ shown in Fig. 9, it is seen that the untreated coal gangue contains quartz, kaolinite and muscovite. After calcination of the mixture at $600{ }^{\circ} \mathrm{C}$, the peaks related to kaolinite disappeared, while the intensity of the peaks related to quartz and muscovite decreased significantly with increase in $\mathrm{CaCO}_{3}$ content. When the mixing ratio exceeds $1: 0.5$, there is no new crystal phase in the calcination except the formation of soluble calcium silicate, indicating that the whole activation process at this stage is a non-equilibrium reaction limited to the destruction of the crystalline structure. Moreover, this destroyed crystal structure will not evolve into crystals again, but will remain amorphous; for example, kaolinite is transformed into amorphous metakaolinite under the influence of $\mathrm{CaCO}_{3}$. Thus, $\mathrm{CaCO}_{3}$ mainly plays a catalytic role in the entire calcination and activation process; the only chemical reaction involving $\mathrm{CaCO}_{3}$ is its reaction with coal gangue on the contact surface, forming soluble calcium silicate.

\subsubsection{Calcination of coal gangue and corn stalk powder mixture}


The FT-IR spectrum of the coal gangue calcined with corn stalk powder, subjected to calcination at $600{ }^{\circ} \mathrm{C}$, mainly displays the vibration absorption peak of the metakaolinite phase (Fig. 10). Compared with the spectrum after calcination of coal gangue alone, the main characteristic peaks of the calcined mixture spectrum-such as the stretching vibration peak of the T-O-T bond at $1050 \mathrm{~cm}^{-1}$-are significantly wider. Moreover, the vibration peak of the $\mathrm{H}-\mathrm{O}-\mathrm{H}$ bond appears at $1638 \mathrm{~cm}^{-1}$, indicating that the organic matter in the corn stalk is continuously removed during calcination. Further, the oxides of corn stalk ash formed during calcination react with the silicon-containing material in the coal gangue to form a soluble silicate, which promotes the activation of $\mathrm{Si}$ in the coal gangue.

Figure 11 shows the XRD spectrum of coal gangue calcined with corn stalk powder, calcined at $600{ }^{\circ} \mathrm{C}$. After calcination, the diffraction peaks related to kaolinite gradually disappear, indicating that the crystal structure of kaolinite has been destroyed; the kaolinite begins to transform into metakaolinite. Moreover, a new mineral component appears in the calcined sample, namely nepheline $\left(\mathrm{K}(\mathrm{Na}, \mathrm{K})_{3} \mathrm{Al}_{4} \mathrm{Si}_{4} \mathrm{O}_{16}\right)$, which indicates that part of the metakaolinite is transformed into silicate. The calcined corn stalk powder contains various oxides such as $\mathrm{CaO}$ and $\mathrm{K}_{2} \mathrm{O}$, which promote the above transformation process. Thus, the oxides in the calcined corn stalk powder can participate in the chemical reactions involved in the further calcination of coal gangue; therefore, the available-Si content of coal gangue calcined with corn stalk powder is significantly higher than that of coal gangue calcined with $\mathrm{CaCO}_{3}$.

\subsubsection{Calcination of coal gangue, $\mathrm{CaCO}_{3}$ and corn stalk powder mixture}

In the multi-factor experiment, the coal gangue-based silicon fertilizer was produced under operating conditions that produced the best results (1:0.3:0.9), and analyzed as shown in Fig. 12. After calcination of the coal gangue, $\mathrm{CaCO}_{3}$ and corn stalk powder mixture at $600{ }^{\circ} \mathrm{C}$, the calcined sample contains not only the original quartz and $\mathrm{CaCO}_{3}$, but also new substances with a large amount of soluble silicon components, i.e., nacrinite $\left(\mathrm{NaAlSiO}_{4}\right)$, potash nepheline $\left(\mathrm{KAISiO}_{4}\right)$, gray wollastonite $\left(\mathrm{Ca}_{5}\left(\mathrm{SiO}_{4}\right)_{2} \mathrm{CO}_{3}\right)$, etc., resulting in the higher available-Si content of the calcined coal gangue. Here, the action of high temperature in the presence of $\mathrm{CaCO} 3$ promotes the destruction of the crystal structure of the gangue, forming a large amount of metakaolinite. The metakaolinite further reacts chemically with the oxides in the corn stalk ash to form soluble silicon acid salt. Thus, under the synergistic effect of $\mathrm{CaCO}_{3}$ and corn stalk powder, the silicon element in coal gangue can be effectively activated.

\section{Conclusion}

This study used $\mathrm{CaCO}_{3}$ and corn stalks as additives to transform coal gangue into coal gangue-based silicon fertilizer through high temperature activation. The influence of the calcination temperature and the mixing ratio on the available-Si in calcined samples was studied using silicomolybdenum blue spectrophotometry, and the activation mechanism of calcined coal gangue with $\mathrm{CaCO}_{3}$ and corn stalk powder was analyzed using XRD and FT-IR technologies.

The available-Si in calcined coal gangue increases with increasing calcination temperature and addition ratio of $\mathrm{CaCO}_{3}$ (or corn stalk powder). At a calcination temperature of $600{ }^{\circ} \mathrm{C}$, the hydroxyl groups and layered structure of the coal gangue are damaged, and the kaolinite begins to transform into metakaolinite, the available-Si content present being less than $10 \%$. Since the destroyed crystal phase continues to remain amorphous, the calcination process after the addition of $\mathrm{CaCO}_{3}$ to the coal gangue at $600{ }^{\circ} \mathrm{C}$ does not include a crystal phase. $\mathrm{CaCO}_{3}$ mainly plays a catalytic role in the entire activation process, only participating in a chemical reaction with coal gangue on the contact surface to form soluble calcium silicate; still, the effective silicon content in the calcined sample is not high, only reaching $12.60 \%$. When coal gangue and corn stalk powder are mixed and calcined at $600{ }^{\circ} \mathrm{C}$, a new mineral component appears in the calcined sample, i.e., nepheline $\left(\mathrm{K}(\mathrm{Na}, \mathrm{K})_{3} \mathrm{Al}_{4} \mathrm{Si}_{4} \mathrm{O}_{16}\right.$. The corn stalk ash contains various oxides such as $\mathrm{CaO}$ and $\mathrm{K}_{2} \mathrm{O}$, which react 
chemically with the minerals in the coal gangue. Meanwhile, the available-Si content increases significantly, reaching $14.56 \%$ at a mixing ratio of $1: 0.9$, which is significantly higher than that with $\mathrm{CaCO}_{3}$. When coal gangue is calcined with $\mathrm{CaCO}_{3}$ and corn stalk powder, a large amount of soluble silicon components are formed under the synergistic effect of $\mathrm{CaCO}_{3}$ and corn stalk powder. When the mixing ratio is 1:0.3:0.9 (coal gangue : $\mathrm{CaCO}_{3}$ : corn stalk powder), the availableSi content in calcined coal gangue reaches $22.97 \%$, the amount of harmful heavy metals present being less than 0.025 $\mathrm{mg} / \mathrm{L}$, thus providing an efficient and safe coal-gangue based silicon fertilizer.

Considering how the coal gangue-based silicon fertilizer could contribute to a modern, and sustainable agriculture system, further studies including planting experiments using silicon fertilizer are necessary, to elucidate the state, variations and relationships between physical, chemical and mineralogical parameters of soils in relation to the silicon fertilizer and its role in plant growth.

\section{Declarations}

Ethical Approval

Not applicable

Consent to Participate

Not applicable

Consent to Publish

Not applicable

Authors Contributions

Bo Lv, and Zeya Zhao: Data curation. Chaojun Fang and Zeya Zhao: Formal analysis, Software simulation. Bo Lv and Bobing Dong: Funding acquisition. Bo Lv, Xiaowei Deng, and Chaojun Fang: Investigation, Methodology. Bo Lv, Bobing Dong, and Zeya Zhao: Resources, Supervision. Bo Lv, Xiaowei Deng and Chaojun Fang: Visualization, Writing - original draft. Zeya Zhao and Xiaowei Deng: Writing-review \& editing.

Funding

The authors acknowledge the financial support by the National Natural Science Foundation of China (No. 51774283, No. 51904096), the research fund of Henan Key Laboratory for Green and Efficient Mining \& Comprehensive Utilization of Mineral Resources (Henan Polytechnic University) (KCF202005), and the research fund of Henan Key Laboratory of Coal Green Conversion (Henan Polytechnic University) (CGCF201906).

Competing interests

The authors declare that they have no competing interests.

Availability of data and materials

Not applicable

\section{References}


1. Bi Y, Xiao L, Liu R (2019) Response of arbuscular mycorrhizal fungi and phosphorus solubilizing bacteria to remediation abandoned solid waste of coal mine. International Journal of Coal Science Technology 06(04):603-610

2. Chen T, Committee XA (2018) Effects of Water-soluble Silicon Fertilizer Spraying on Rice Yield and Economic Characters. Hunan Agricultural Sciences (11): 53-55

3. Cai DL (2017) Research and application development of silicon fertilizer at home and abroad. Phosphate Compound Fertilizer 32(1):37-39

4. Castellano M, Turturro A, Riani P, Montanari T, Finocchio E (2010) Bulk and surface properties of commercial kaolins. Appl Clay Sci 48(3):446-454

5. Dopson M, Lövgren L, Boström D (2009) Silicate mineral dissolution in the presence of acidophilic microorganisms: implications for heap bioleaching. Hydrometallurgy 96(4):288-293

6. Gao Y, Huang H, Tang W, Liu X, Yang X, Zhang J (2015) Preparation and characterization of a novel porous silicate material from coal gangue. Microporous Mesoporous Mater 217:210-218

7. Guo Y, Yan K, Cui L, Cheng F (2016) Improved extraction of alumina from coal gangue by surface mechanically grinding modification. Powder Technol 302:33-41

8. Liu YL, He XM, Hu HM, Zhang QW (2020) Cogrinding with alkaline metal salts to enhance the reactivity of silicate mineral to serve as silicon fertilizer. Chem Phys Lett 747:137347

9. Lee YB, Kim PJ (2006) Effects of silicate fertilizer on increasing phosphorus availability in salt accumulated soil during chinese cabbage cultivation. Korean Journal of Soil Science Fertilizer 39(1):8-14

10. Li XL, Yang L, Zhao ZC, Zhang XM, Chen L, Hu Y et al (2014) Study on Comparative of calcium carbonate mineral medicines by infrared spectrum. Lishizhen Medicine and Materia Medica Research (10): 2418-2419

11. Li Y, Yao Y, Liu X, Sun H, Wen N (2013) Improvement on pozzolanic reactivity of coal gangue by integrated thermal and chemical activation. Fuel 109:527-533

12. Li L, Zhang Y, Zhang Y, Sun J, Hao Z (2016) The thermal activation process of coal gangue selected from zhungeer in china. Journal of Thermal Analysis Calorimetry 126(3):1-8

13. Li J, Yang H, Tong L (2021) Microbial solubilization of gangue minerals and their influence on pyrite bio-oxidation. Geochemistry (3-4): 125790

14. Mandlik R, Thakral V, Raturi G, Shinde S, Nikoli'c M, Tripathi DK, Sonah H, Deshmukh R (2020) Significance of silicon uptake, transport, and deposition in plants. J Exp Bot 71(21):6703-6718

15. Makabe-Sasaki S, Kakuda KI, Sasaki Y, Ando H (2014) Effects of slag silicate fertilizer on silicon content of rice plants grown in paddy fields on the shounai plain, yamagata, japan. Soil Science Plant Nutrition 60(5):708-721

16. Makó E, Senkár Z, Kristóf J (2006) Surface modification of mechanochemically activated kaolinites by selective leaching. J Colloid Interface Sci 294(2):362-370

17. Markovic S, Dondur V, Dimitrijevic R (2003) FT-IR spectroscopy of framework aluminosilicate structures: carnegieite and pure sodium nepheline. J Mol Struct 654(1):223-234

18. Ning D, Liang Y, Liu Z, Xiao J, Duan A (2016) Impacts of steel-slag-based silicate fertilizer on soil acidity and silicon availability and metals-immobilization in a paddy soil. Plos One 11(12):e0168163

19. Pati S, Pal B, Badole S, Hazra GC, Mandal B (2016) Effect of silicon fertilization on growth, yield, and nutrient uptake of rice. Communications in Soil Science Plant Analysis 47(3):284-290

20. Peng WS, Liu GK (1982) Mineral infrared spectroscopy atlas. Science Press, Beijing

21. Song ZL, Wang HL, Strong PJ et al (2014) Phytolith carbon sequestration in china's croplands. Eur J Agron 53:10-15

22. Samaddar S, Truu J, Chatterjee P, Truu M, Kim K, Kim S, Seshadri S, Sa T (2019) Long-term silicate fertilization increases the abundance of Actinobacterial population in paddy soils. Biol Fertil Soils 55(2):109-120

Page $12 / 24$ 
23. Said A, Zhang Q, Qu J, Liu Y, Lei Z, Hu H et al (2018) Mechanochemical activation of phlogopite to directly produce slow-release potassium fertilizer. Appl Clay Sci 165:77-81

24. Sun HB (2008) Preparation organic multi-fertilizer contain silicon from coal gangue/ coalash and crop straw. Dissertation, Shandong University of Science and Technology

25. Wang S, Wang X (2018) Potentially useful elements (Al, Fe, Ga, Ge, U) in coal gangue: a case study in Weibei coal mining area, Shaanxi Province, northwestern China. Environmental Science Pollution Research 25(12):11893-11904

26. Wang B, Ma Y, Lee X, Wu P, Chen M (2020) Environmental-friendly coal gangue-biochar composites reclaiming phosphate from water as a slow-release fertilizer. Sci Total Environ 758:143664

27. Wang SQ, Chun-Mei GU, Zhao HH, Zhao LM, Wang LP, Wang H (2010) Research and application prospects of microsilicon fertilizer on rice production. North Rice 40(5):73-79

28. Xiao W, Liu Y, Qiang Z, Matichenkov V, Dstl M (2016) Efficacy of Si fertilization to modulate the heavy metals absorption by barley (Hordeum vulgare L.) and pea (Pisum sativum L.). Environmental Science Pollution Research International 23(20):1-6

29. Xiao ZX, Peng M, Mei YC, Tan L, Liang YC (2021) Effect of organosilicone and mineral silicon fertilizers on chemical forms of cadmium and lead in soil and their accumulation in rice. Environ Pollut 283:117107

30. Yan GC, Nikolic M, Mu-Jun YE, Xiao ZX, Liang YC (2018) Silicon acquisition and accumulation in plant and its significance for agriculture. Journal of Integrative Agriculture 17:2138-2150

31. Yao Y, Hamada E, Sato K, Akiyama T, Yoneyama T (2014) Identification of the major constituents of fused potassium silicate fertilizer. ISIJ international 54(4):990-993

32. Yan XB (2018) Research on the evolution of functional groups during coal gangue reaction. Dissertation, Xi'an University of Science and Technology

33. Zhu DD, Xue B, Jiang YS, Wei CD (2019) Using chemical experiments and plant uptake to prove the feasibility and stability of coal gasification fine slag as silicon fertilizer. Environ Sci Pollut Res Int 26(6):5925-5933

\section{Figures}

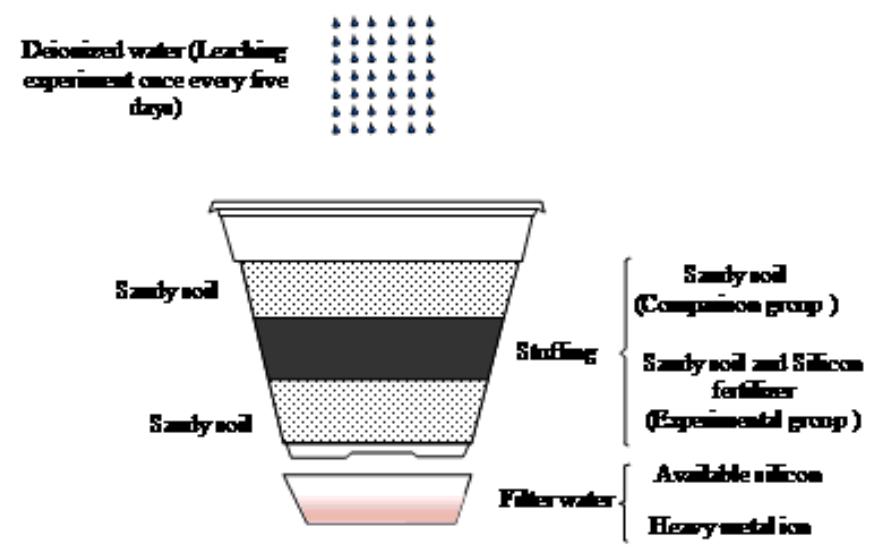

Figure 1

Schematic diagram of leaching experiment. 

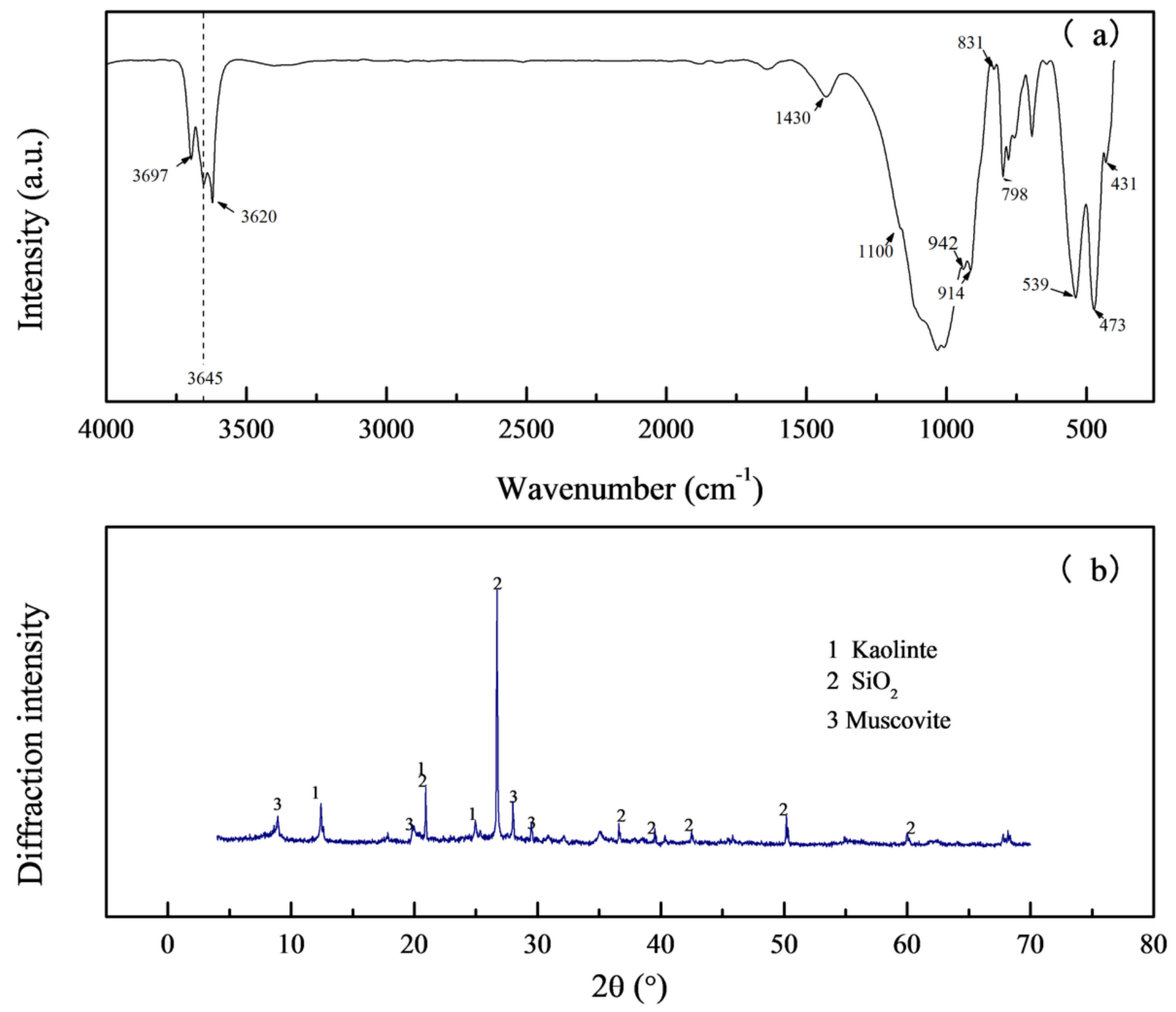

Figure 2

The mineral composition and crystal structure analysis of coal gangue: (a) infrared spectrum; (b) X-ray diffraction spectrum. 


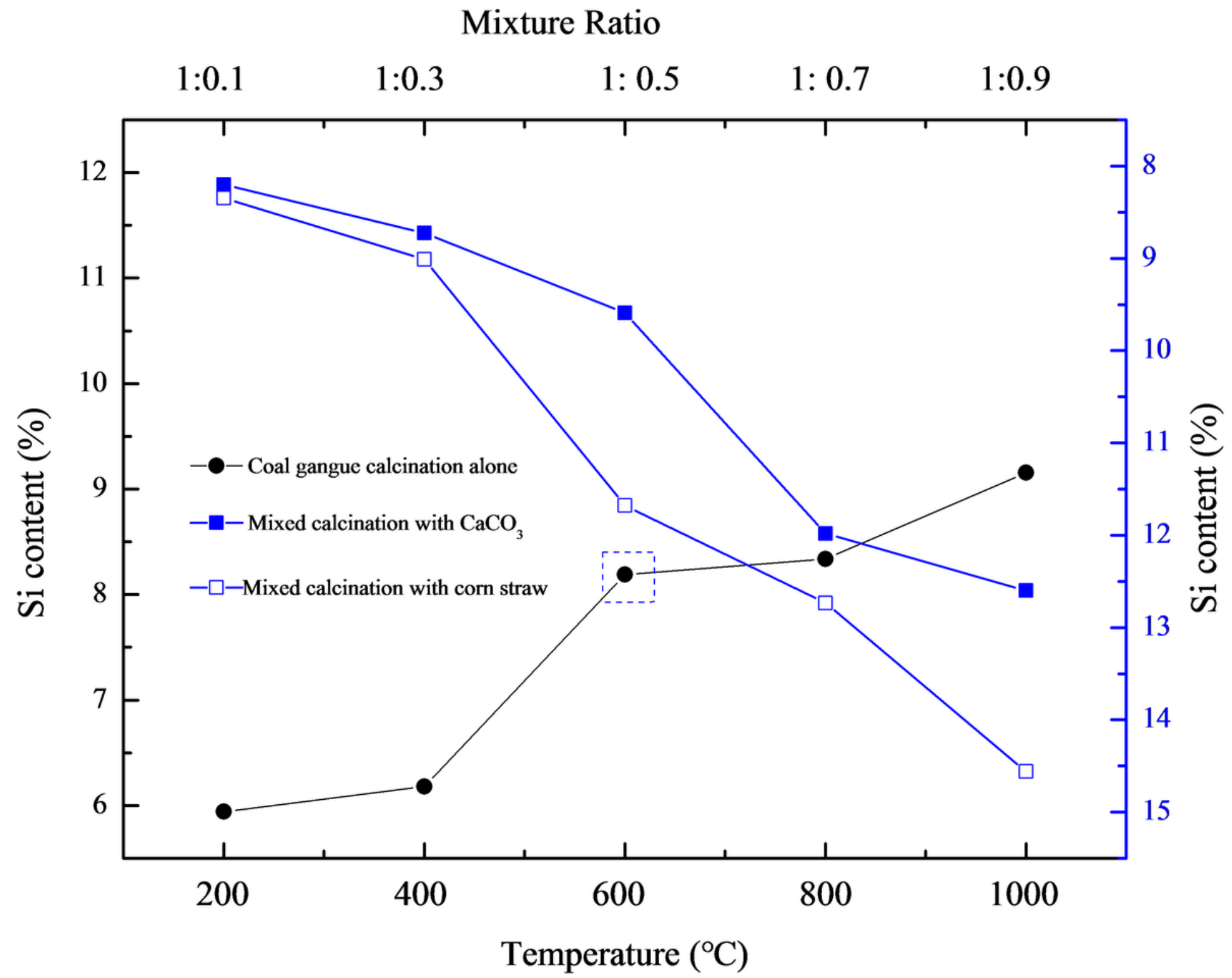

Figure 3

Available-Si content of calcined coal gangue under different conditions. 


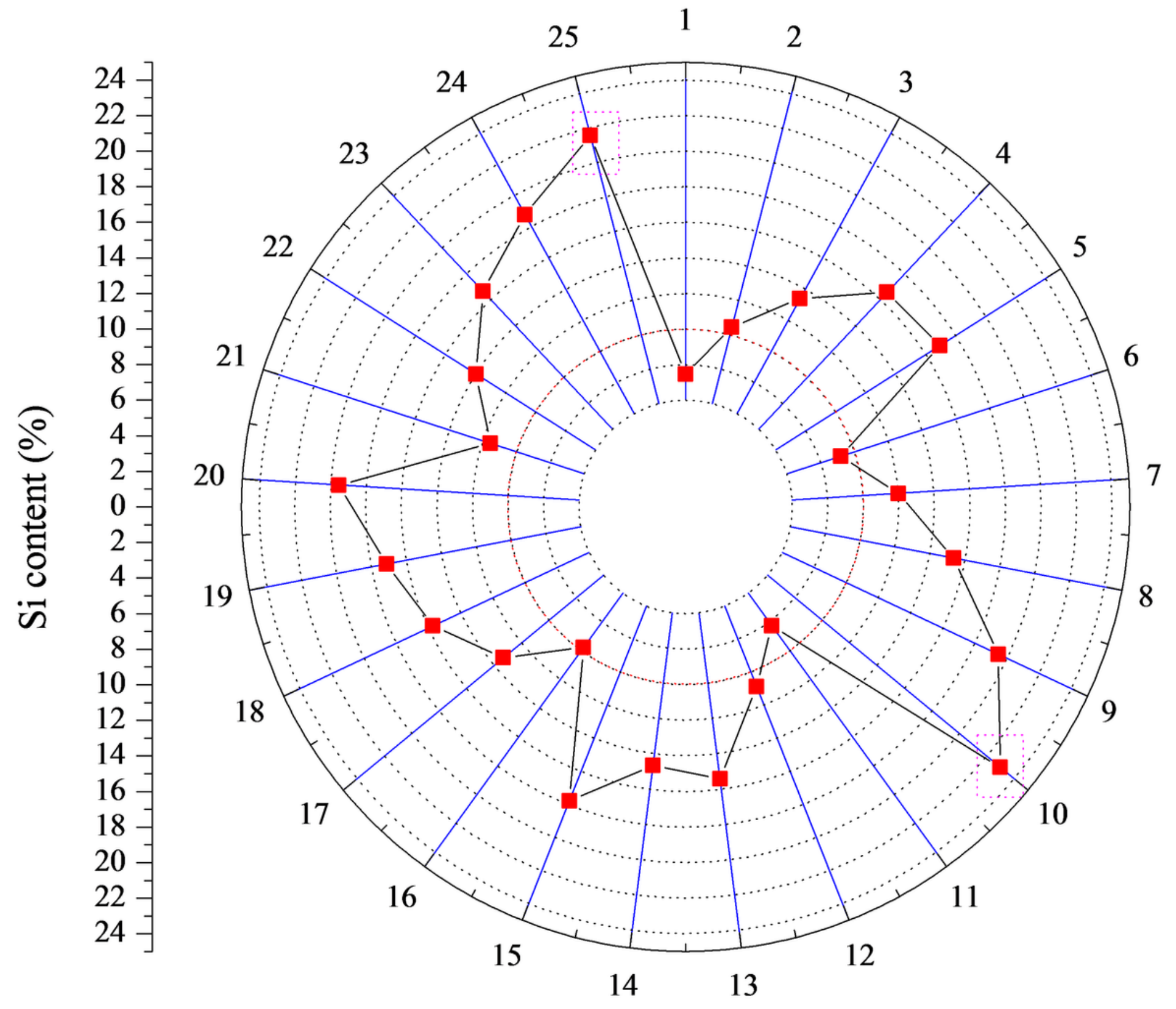

Figure 4

Extraction rate of available-Si under different conditions. 
Time (d)

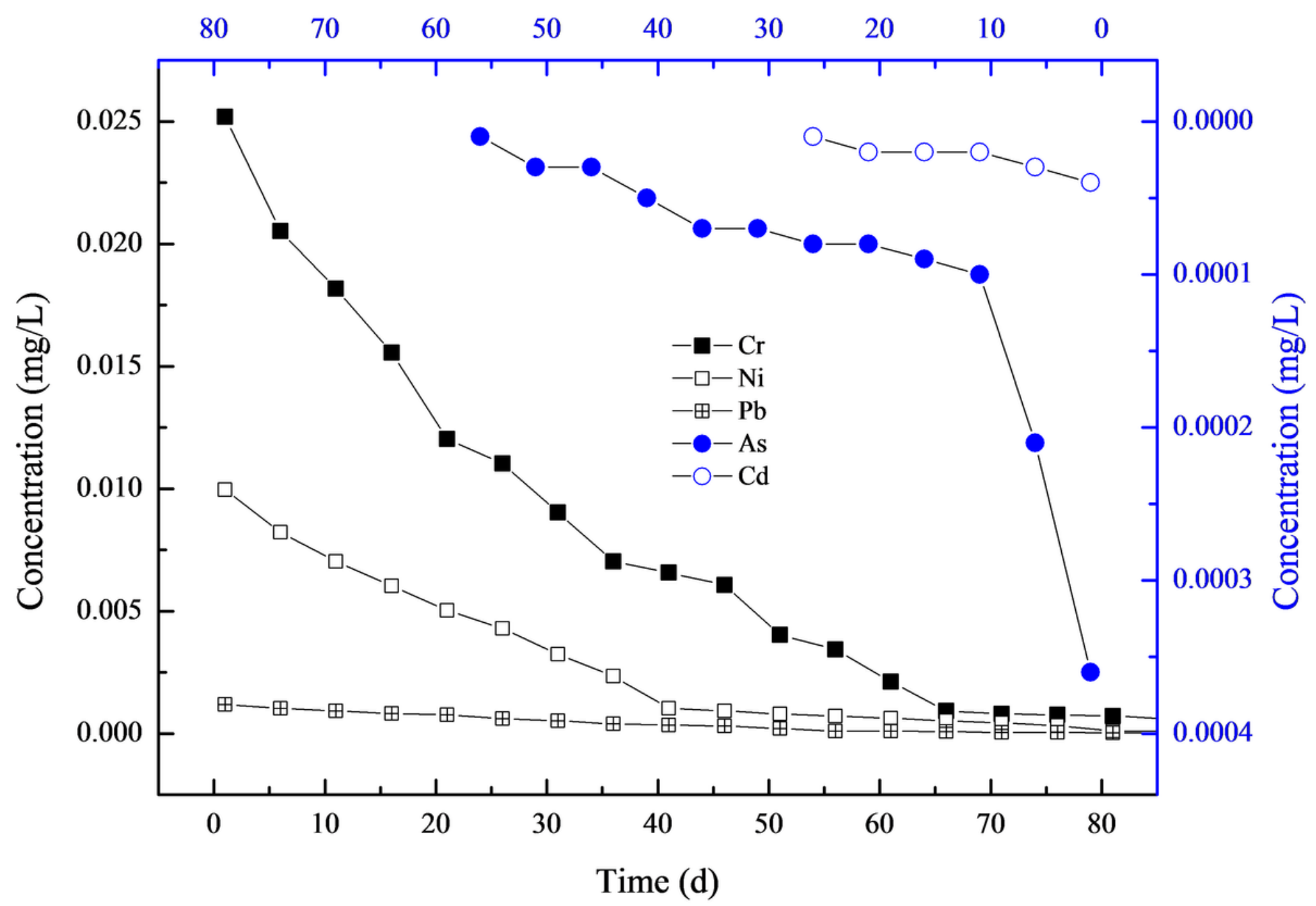

Figure 5

The content of harmful heavy metal ions in the filtrate. 


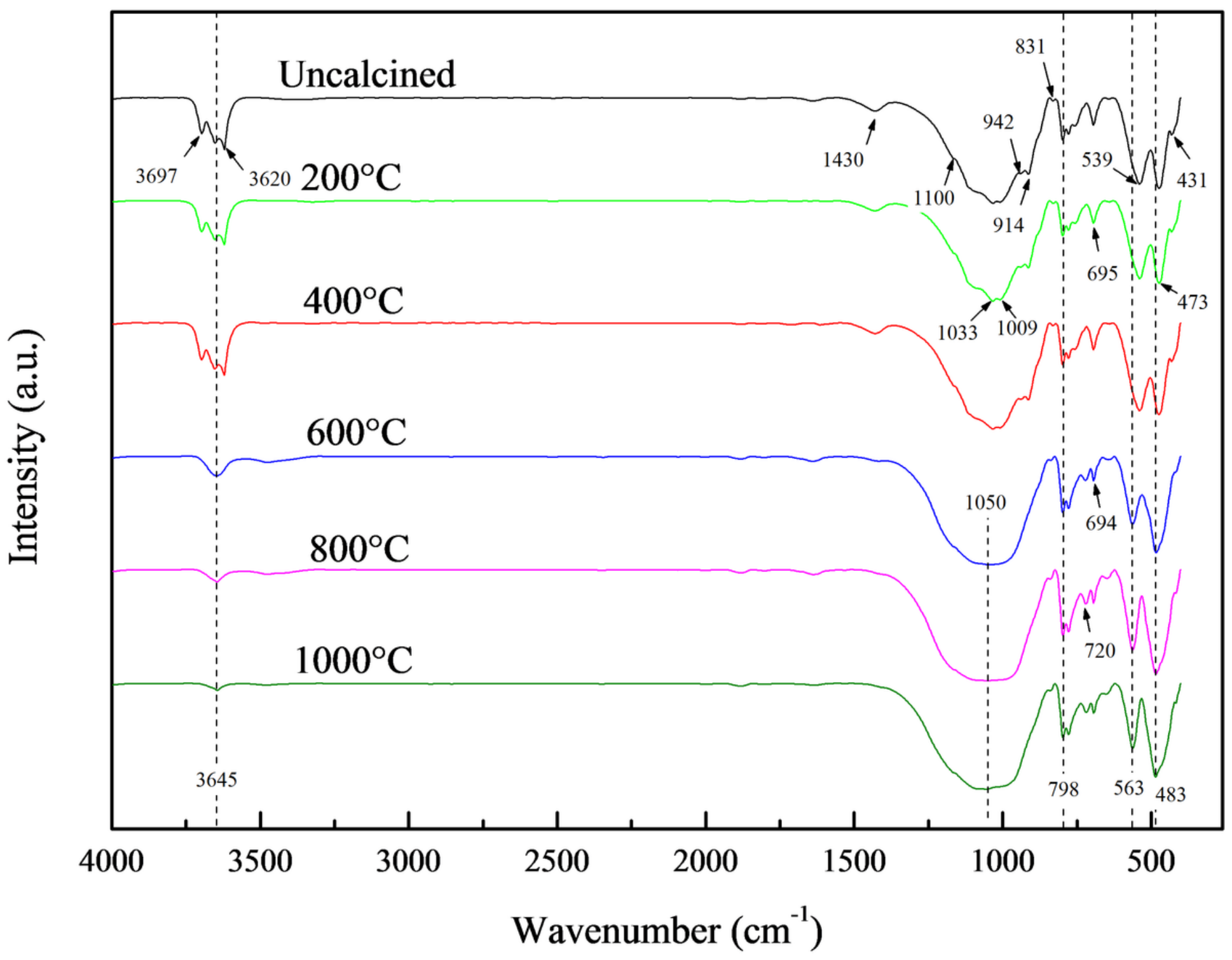

Figure 6

FT-IR spectra of calcined samples at different temperatures. 


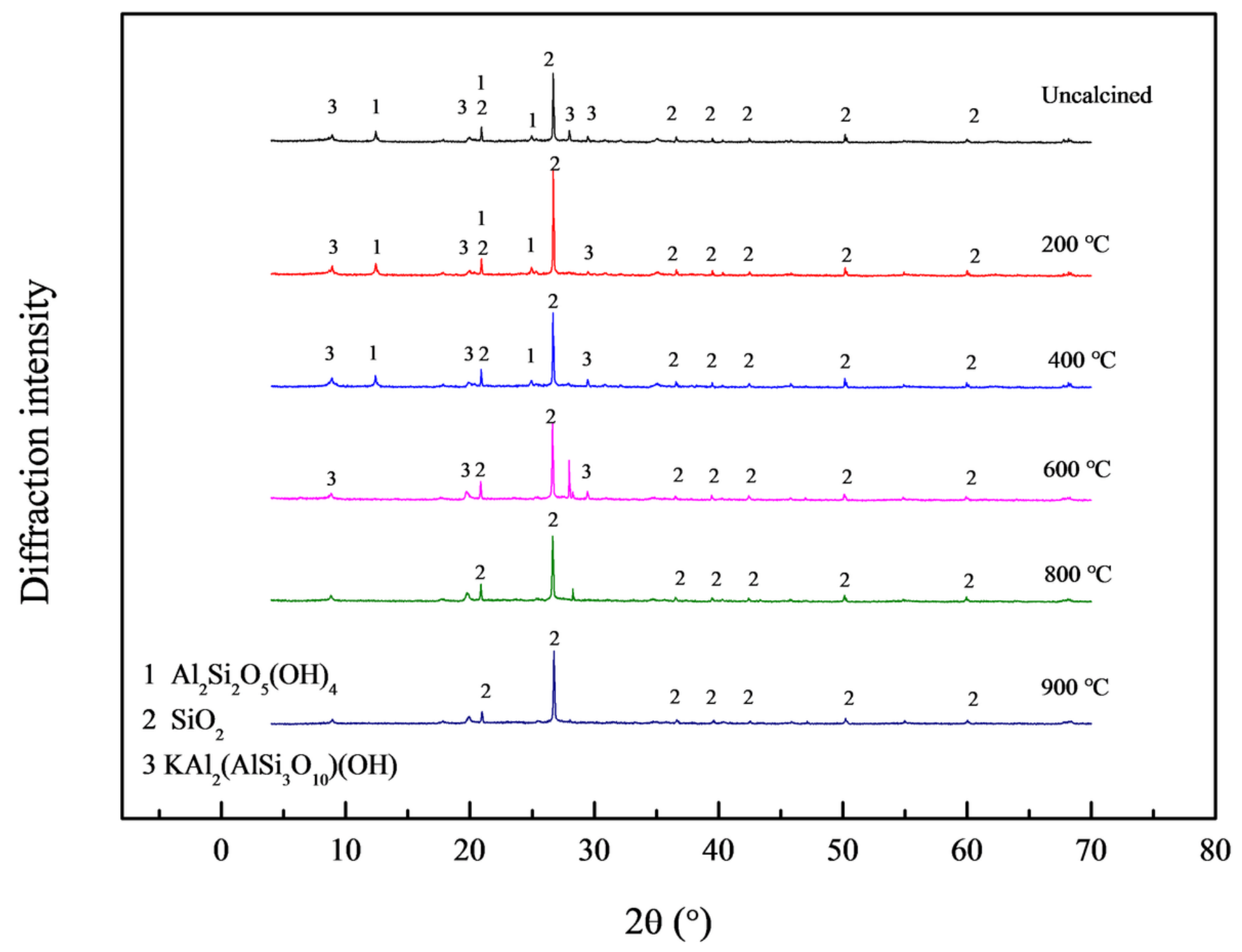

Figure 7

XRD spectra of calcined samples at different temperatures. 


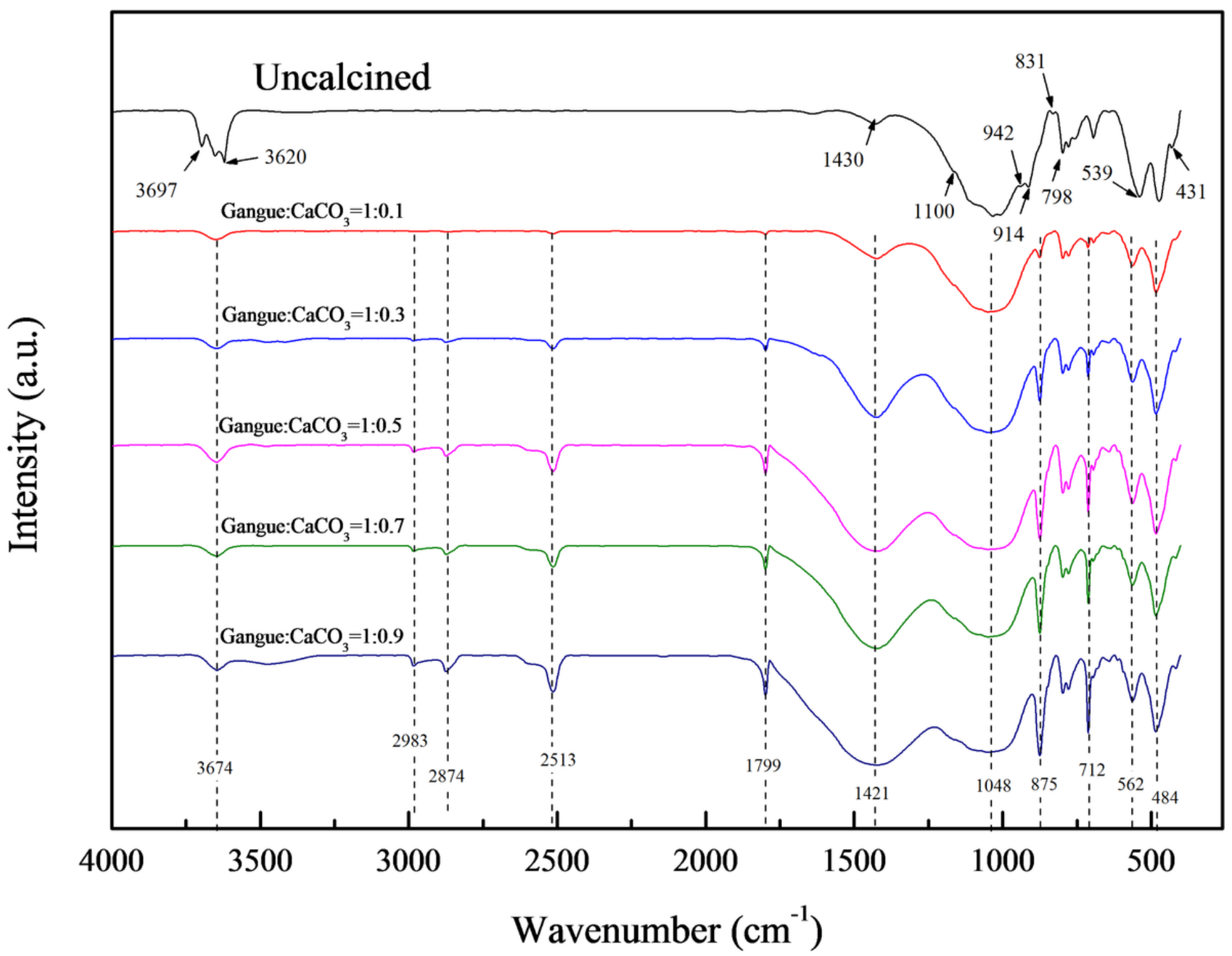

Figure 8

FT-IR spectra of coal gangue calcined with $\mathrm{CaCO}$. 


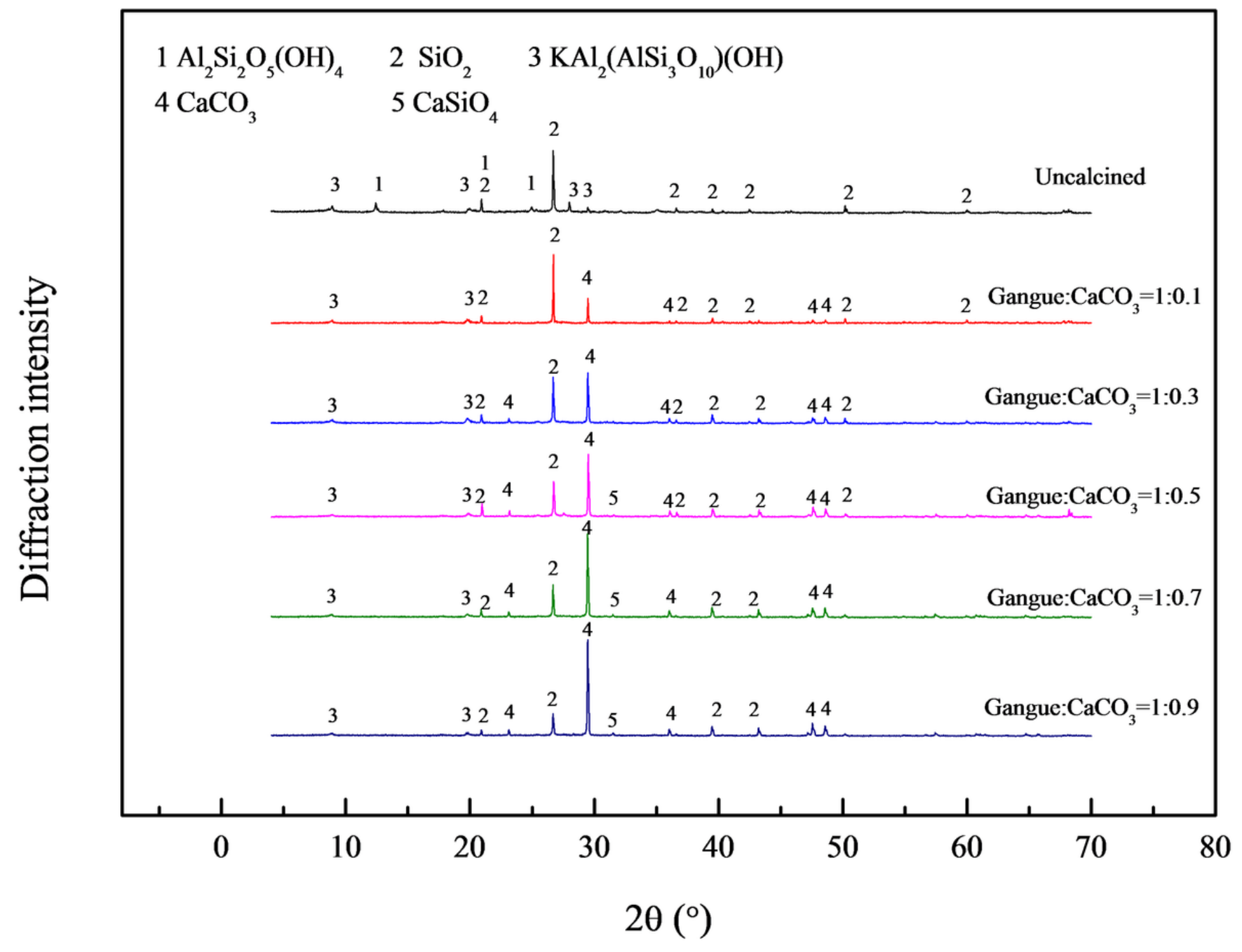

Figure 9

XRD spectra of coal gangue calcined with $\mathrm{CaCO}$. 


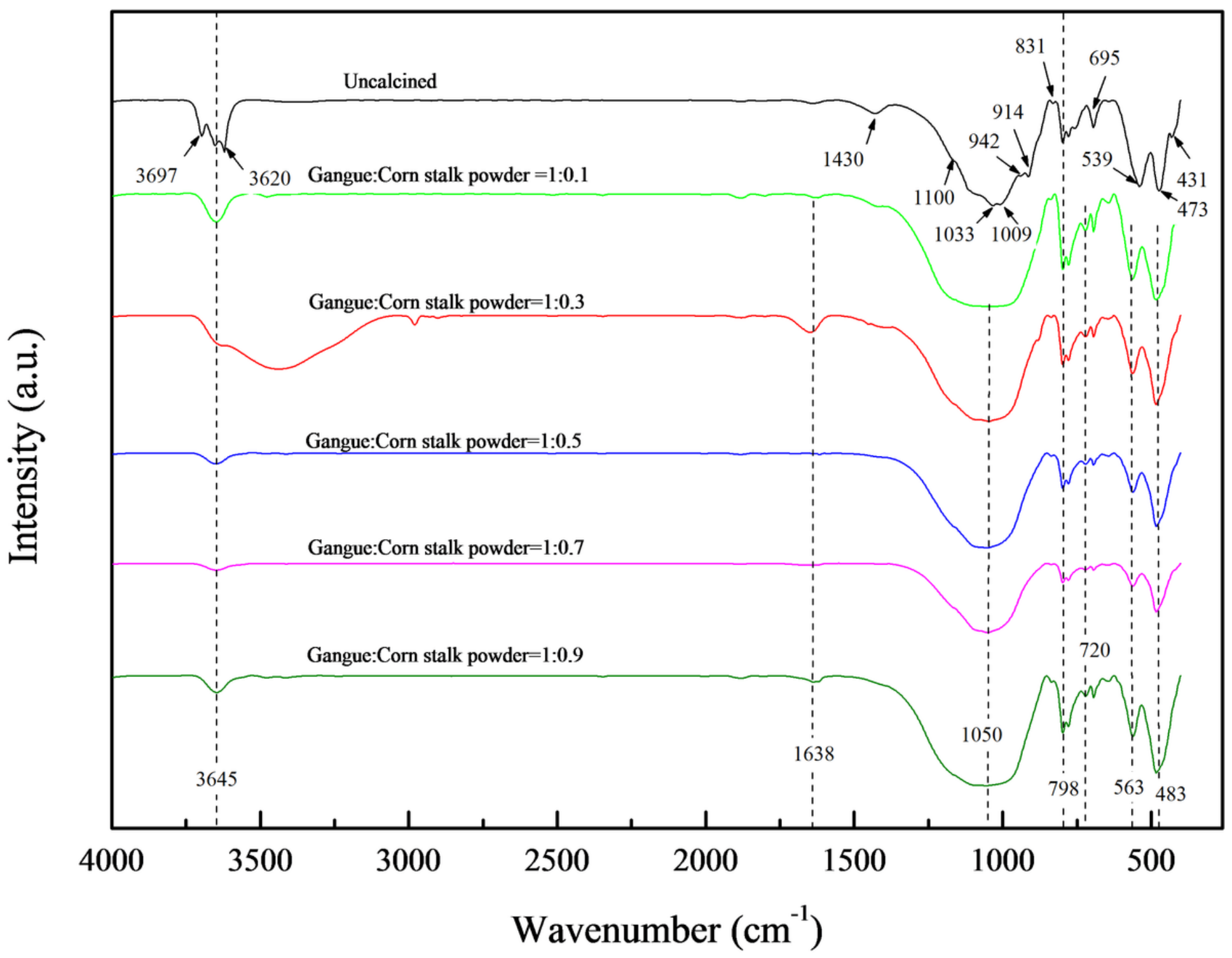

Figure 10

FT-IR spectra of coal gangue calcined with corn stalk powder. 


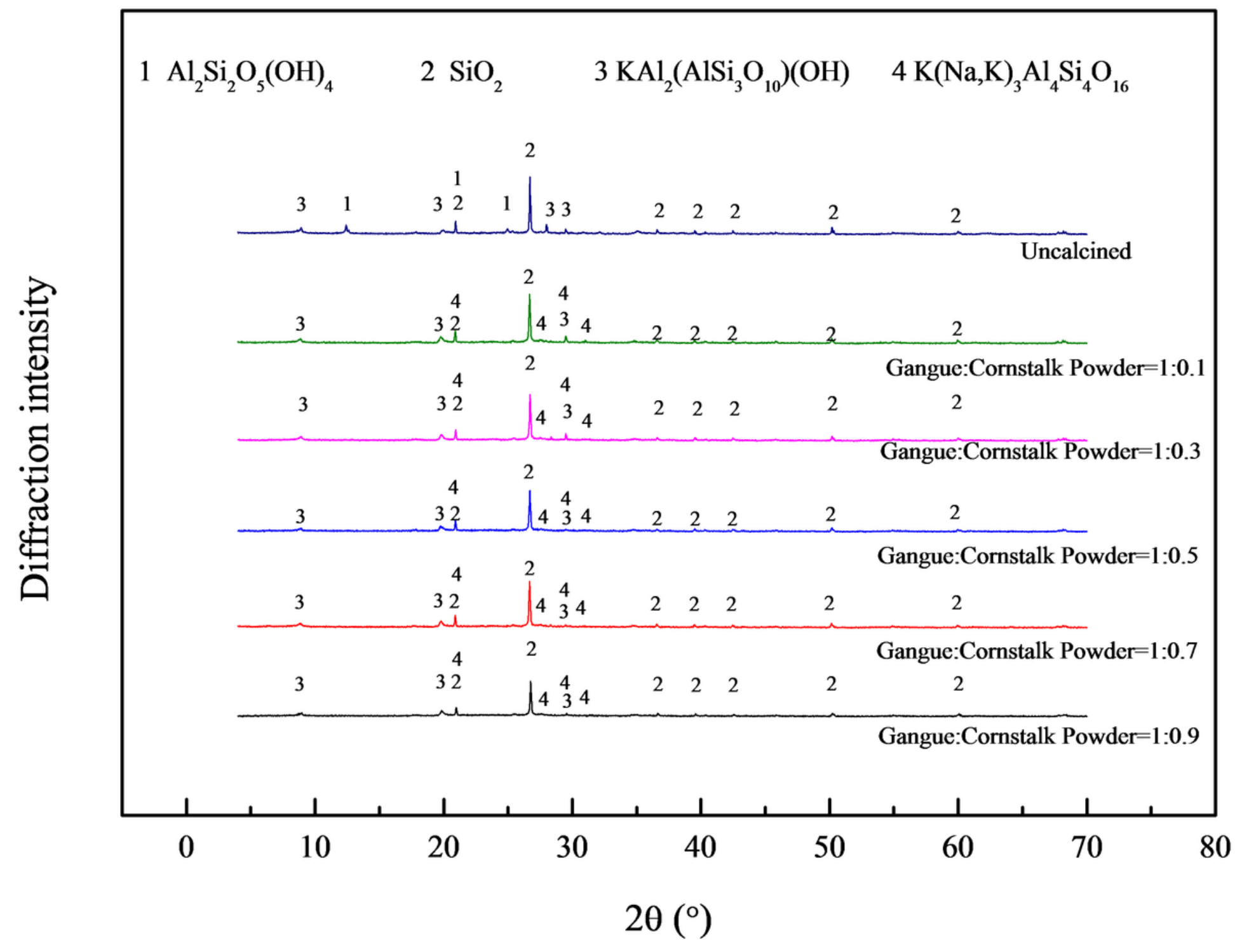

Figure 11

XRD spectra of coal gangue calcined with corn stalk powder. 


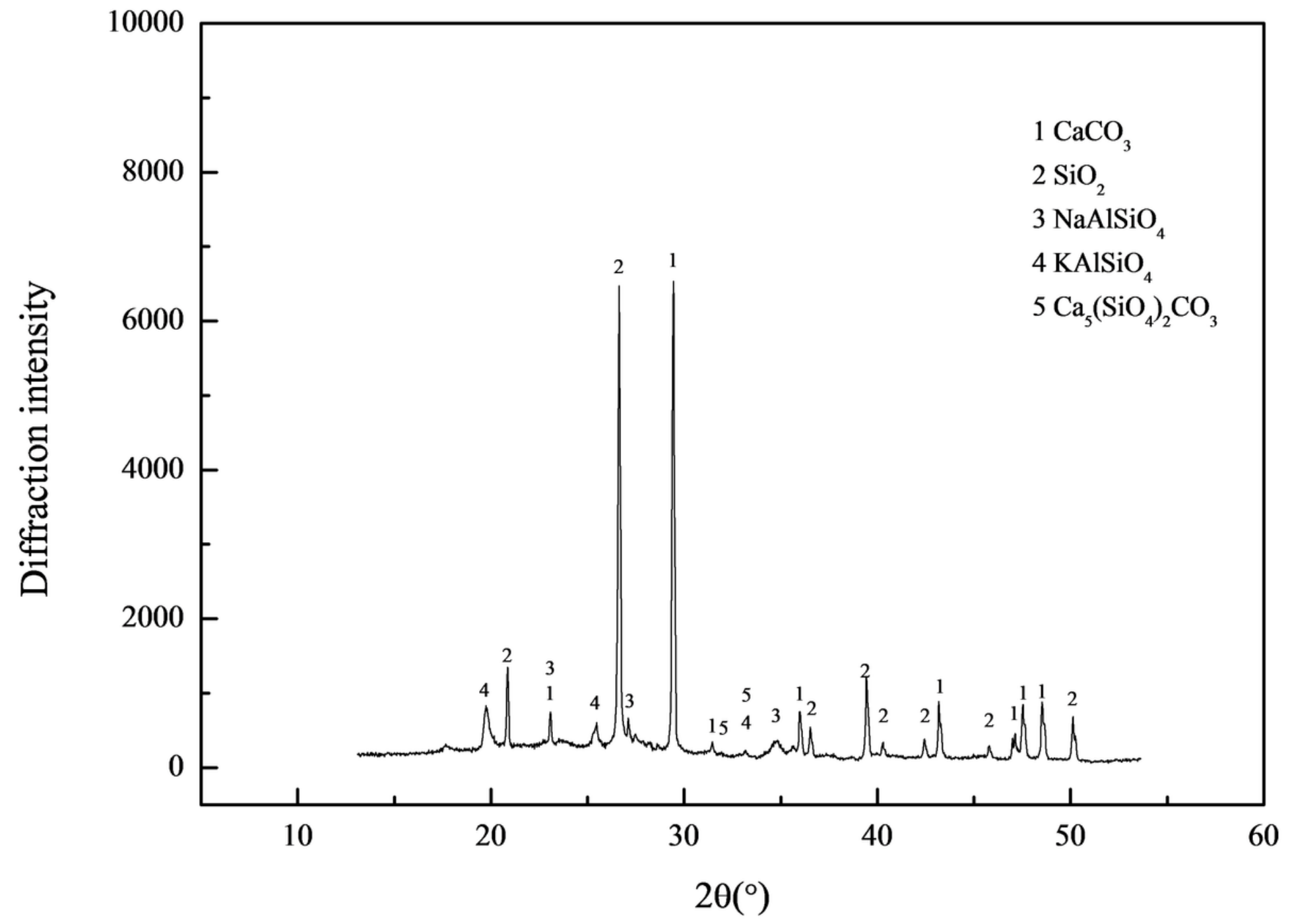

Figure 12

XRD spectrum of coal gangue calcined with $\mathrm{CaCO} 3$ and corn stalk powder. 